\title{
The accident and emergency department as a single portal of entry for the reassessment of all trauma patients transferred to specialist units
}

\author{
P M O'Connor, J A Steele, C H Dearden, L G Rocke, R B Fisher
}

\begin{abstract}
127 patients who were transferred to a regional referral centre for specialist treatment within 48 h of serious injury were reassessed on arrival in the receiving accident and emergency department by a trauma team. 80 transferred patients $(63 \%)$ required intervention in the accident and emergency department to complete assessment or resuscitation. In view of the well recognised difficulties in managing patients with multiple trauma and the possibility that initially occult injuries may become clinically significant during transport, transferred trauma patients should be reassessed in the accident and emergency department of the receiving hospital by a trauma team consisting of senior medical staff experienced in all aspects of trauma care.

( 7 Accid Emerg Med 1996;13:9-10)
\end{abstract}

Key terms: trauma management; accident and emergency department; transport.

Until this study was begun it was the practice in our hospital for transferred trauma patients to go directly to the specialist unit which was to provide care. However, previous studies have shown that multiply injuried patients are notoriously difficult to assess and an initially stable patient may deteriorate over a period of hours, developing clinical signs not apparent on initial presentation. ${ }^{1-3}$ Patients referred to specialist centres for treatment of what is apparently their major injury may have other occult injuries which can go unrecognised in the primary hospital. ${ }^{4}$ The hospital trauma committee attempted to circumvent these difficulties by requesting that for a trial period of one year all transferred trauma patients should enter the hospital through a single portal, namely the accident and emergency department. On arrival they were to be assessed by a trauma team.

This paper presents the results of this change in policy in terms of transferred patients who arrived with previously undiagnosed injuries, incomplete investigations, or inadequate resuscitation.

\section{Methods}

We studied 127 consecutive seriously injured patients transferred to a regional referral centre over a period of one year. These patients were assessed on arrival in the accident and emergency department by the "trauma team" consisting of a senior member of the department (consultant, senior registrar, or registrar) and a senior general surgeon (senior registrar or registrar). An anaestetist was present when required. Basic observations of blood pressure, pulse, and respiration were recorded. ATLS guidelines were used as the acceptable standard for initial patient management. Other aspects of pretransfer care were noted. These including adequacy of intravenous access, adequacy of fluid replacement, $x$ rays (cervical spine, chest, and pelvic, where relevant), and diagnostic peritoneal lavage (where indicated).

Any intervention undertaken in the receiving accident and emergency unit to complete the initial assessment and resuscitation was recorded, and undiagnosed injuries detected in the receiving department were also noted Transfer times were recorded, that is, from the time of the accident until the time of arrival in the receiving accident and emergency department.

\section{Results}

Eighty patients $(63 \%)$ required intervention by the trauma team in the accident and emergency department to complete assessment and resuscitation. The aetiology of the injuries is given in table 1 and the destinations of the transferred patients in table 2 .

\section{OMISSIONS IN TREATMENT}

Thirteen patients $(10 \%)$ were severely hypovolaemic (class 3 or 4 haemorrhage), having a systolic blood pressure of less than $90 \mathrm{~mm} \mathrm{Hg}$ and a pulse of greater than 100 beats/min. Twenty seven patients $(21 \%)$ had inadequate intravenous access or none at all.

\section{Table 1 Aetiology of injuries}

\begin{tabular}{lc}
\hline Road traffic accident & $69 \%$ \\
Fall & $11 \%$ \\
Assault & $10 \%$ \\
Gunshot wound & $6 \%$ \\
Bomb blast & $2 \%$ \\
Other & $2 \%$ \\
\hline \multicolumn{2}{|l}{ Distribution of injury severity scores (ISS) } \\
\hline ISS 0-8 \\
ISS 9-15 $16 \%$ \\
ISS 16 and over & $12 \%$ \\
\hline
\end{tabular}

Table 2 Destination of transferred patients by specialty

\begin{tabular}{ll}
\hline Specialty & Number of patients \\
\hline Fractures & 90 \\
Neurosurgery & 25 \\
Thoracic surgery & 8 \\
Maxillo-facial & 4 \\
\hline
\end{tabular}


Table 3 Undiagnosed injuries

\begin{tabular}{llll}
\hline Site & No of patients & Injury & Comments \\
\hline Chest & 1 & Bilateral pneumothoraces with multiple rib fractures & Required ventilation \\
& 1 & Pulmonary contusion & \\
& 1 & Haemothorax with pulmonary contusion & Required ventilation \\
& 1 & Blast lung & Required ventilation \\
& 1 & Fat embolism & \\
Abdominal & 1 & Ruptured spleen & Required splenectomy \\
& 1 & Intra-abdominal bleeding & All required laparotomy and \\
definitive surgery & Required fixation. \\
Skeletal & 1 & Odontoid peg fracture & One severe disrupted ring fracture \\
& 1 & Fractured pelvis & \\
& 1 & Fractured ankle & \\
& 1 & Fractured scapula & \\
& 1 & Fractured patella & \\
& 1 & &
\end{tabular}

OMISSIONS IN INVESTIGASTION

Nineteen patients (15\%) were transferred without diagnostic peritoneal lavage (although indicated by ATLS guidelines). Thirty three patients $(26 \%)$ were transferred without cervical spine, chest, or pelvic $x$ rays.

The median transfer time was $5.5 \mathrm{~h}$ from the time of the accident to the time of arrival in the accident and emergency department of the regional unit.

\section{UNDIAGNOSED INJURIES}

Thirteen patients $(10 \%)$ had undiagnosed injuries, of which over $75 \%$ were serious or life threatening (see table 3). Both patients with undiagnosed pneumothoraces and rib fractures were subsequently ventilated.

\section{Discussion}

Many problems are associated with transferred trauma patients. Gentleman and Jennet's 1986-1987 audit of patients transferred with severe head injuries showed that $7 \%$ of patients suffered from hypotension in transfer, while $10 \%$ had inadequately managed multiple injuries. ${ }^{5}$ Such studies underline the need for improvement in trauma care associated with the transfer of multiply injured patients. Our study reiterates these problems and highlights the need for further intervention following transfer. Assessment should be undertaken by senior staff trained in all aspects of trauma care, that is, "generalists" as opposed to "specialists". The accident and emergency department is an ideal setting for such reassessment, with all resuscitation and emergency investigation equipment immediately available, and experienced nursing and medical staff at hand. We suggest that such reassessment of these patients by a trauma team, in the setting of the accident and emergency department, contributes significantly to an improved quality of patient care.

Based on a paper presented to the 1993 Annual Meeting of the British Association of Accident and Emergency Medicine.

1 Enderson BL, Reath DB, Meadors J, Dallas W, De Boo JM Maull KI. The tertiary trauma survey: A prospective study of missed injury. F Trauma 1990;30:666-70.

2 Lang EK. Intra-abdominal and retroperitoneal organ injuries diagnosed on dynamic computed tomogram obtained for assessment of renal trauma. $\mathcal{F}$ Trauma 1990;30:1161-8.

3 Mackersie RC, Tiwary AD, Shackford SR, Hott DB. Intraabdominal injury following blunt trauma. Identifying the high risk patient using objective risk factors. Arch Surg 1989;124:809-13.

4 Gentleman D, Jennett B. Hazards of inter-hospital transfer of comatose head-injured patients. Lancet 1981;ii:853-5.

5 Gentleman D, Jennett B. Audit of transfer of unconscious head-injured patients to a neurosurgical unit. Lancet head-injured patien 